\title{
Response to the Elizabeth Green Article
}

\author{
Mark Saul, Coordinating Editor
}

On July 23, 2014, the New York Times Magazine carried an article by journalist Elizabeth Green entitled "Why Do Americans Stink at Math?" (Green's article can be found at: www. nytimes.com/2014/07/27/magazine/why-do-americans-stink-at-math. htm1?_r=0). The (somewhat provocative) question posed by Green has since been resonating with the mathematical community. We present here reactions to the article from six diverse points of view.

\section{Hyman Bass}

Elizabeth Green's article and the book from which it was extracted weave two different, but confluent, narratives. One, the most publicly visible, is about a long history of efforts to reform and thereby improve American education, each one ending in perceived failure. The other is about teaching, as a complex professional craft, and the professional culture needed to prepare and sustain its practitioners. This last story is well understood by a few American visionaries, but its broad realization is a mainly foreign account, illustrated in Green's article in the case of Japan. It is this story of teaching, too little understood in the US, that is the neglected foundation of educational reform and that Green has skillfully done much to make available for more nuanced public awareness and discussion. I will discuss these two narratives in turn.

Educational reforms are undertaken for a mixture of two reasons: changed economic and social conditions elevate the demands on public education or public education is judged to be falling

Mark Saul is with the Courant Institute of Mathematical Sciences, NYU, and the Mathematical Association of America. His email address is marksau1@earth1ink.net.

Hyman Bass is Samuel Eilenberg Distinguished University Professor of Mathematics and Mathematics Education, University of Michigan. His email address is hybass@umi ch. edu. DOI: http://dx.doi.org/10.1090/noti1252 short of current public expectations, as is now the case. The "New Math" reforms were in part a response to perceived post-Sputnik security threats. (And though somewhat naïve in concept, New Math was not a complete failure.) The more recent reforms, of which the Common Core is the latest incarnation, date from the threatened economic decay proclaimed in A Nation at Risk.

The US presents particular obstacles to achieving educational improvement at a national scale, deriving from its social and economic diversity and also from an entrenched tradition of "local control," which precludes a federal role in any primary initiatives. Yet to achieve effective reform at scale requires some national coherence. This was a principal aim of the Common Core, embodied in the word "Common." Fractions are the same in Florida and Montana; it makes little sense in a highly mobile population for the math curriculum to change at state lines. It would be like building a national railway system with different gauge tracks in each state. Moreover, sponsorship of the Common Core by the National Governors Association and the Council of Chief State School Officers squarely places ownership with the (collective) states, thus honoring local control. The current debates about the Common Core are, on close inspection, not so much about the standards but about the testing regimes that federal policies seek to encourage. If the Common Core is discarded, we will need standards to replace them, and it is hard to imagine 
better or more coherent standards emerging, not to mention the tragic loss of time and expert effort. Educational reforms comprise four fundamental components; standards, which are an expression of learning goals, and their development across grade levels; curriculum materials to provide teachers with instructional resources to reach those goals; assessments as a means to monitor progress toward achieving the goals; and professional development (including preparation) of teachers to give them the knowledge, skills, and other resources to enact the standards-based instruction. The first three of these-standards, curriculum, and assessmentscan be achieved, with reasonable funding, by groups of experts over two to three years.

The last component of reform, the professional development of teachers, is of a totally different order of magnitude if the standards represent a substantial change, as is the case with the Common Core. It is the teachers, ultimately, who implement reforms. The nearly four million American teachers constitute the largest US profession! Adequately elevating the knowledge and skills of these mostly poorly prepared practitioners demands a cost in money and time (decades) that dwarfs the investment in the other reform components. This helps explain why this component has been consistently shortchanged by an impatient and poorly informed public and by politicians with short election horizons. This has been at the root of every failed reform, whatever the quality or promise of the other components.

There is a growing awareness in the research community that teaching quality, achieved at scale, is the central and, so far, intractable challenge to American educational improvement. But even with that awareness, there is not a well-developed knowledge base for how to bring that about. There are various policy levers that aim to provide incentives for teachers and schools to improve their instruction, but incentives and good intentions absent necessary knowledge and skills do not suffice. There is a small number of scholars, deeply connected to practice, who have been closely studied by Green and who have been developing ideas for how to provide professional training and sustained support, at scale, to the teaching profession. It is this very significant development that has received too little public notice and that Elizabeth Green's article, and the book from which it was extracted have vividly illuminated.

\section{Hung-Hsi Wu}

\section{"All You Have to Do Is Teach Better"}

This is a partial summary of a longer paper, "Building better mathematics teachers," available at math. berkeley.edu/ wu/AMSNotices_2014.pdf. I am indebted to Dick Askey and Larry Francis for their invaluable feedback.

In an article in the New York Times Magazine [Green], Elizabeth Green claims that Americans "stink at math" because "the traditional way of teaching math simply doesn't work." The only way out, according to her, is to follow the prescription given out by NCTM (National Council of Teachers of Mathematics) in the 1980s to radically change the way teachers teach math. It is that simple: teach better and improvement in math education will follow.

But is it?

If Americans do "stink" at math, clearly it is because they find the math in school to be unlearnable. Many factors contribute to this sorry state of affairs; pedagogical flaws may well be one of them, but they are not the dominant factor. For the past four decades or so the mathematics contained in standard textbooks (to be called Textbook School Mathematics [Wu], TSM for short) has played havoc with the teaching and learning of school mathematics. The impact of TSM on every aspect of school mathematics is so overwhelming that it renders all other considerations almost irrelevant.

TSM distinguishes itself from (correct) school mathematics by not offering definitions of basic mathematical concepts such as fraction, percent, or constant rate; by the absence of correct reasoning for basic facts such as why the product of two negative numbers is positive or why the graph of a linear equation is a line; by blurring the line between heuristics and proof in numerous instances, including $a^{0}=1$ for a positive number $a, a / b=a \div b$ for a fraction $a / b$, and the fact that two lines (neither vertical) are perpendicular if and only if the product of their slopes is -1 ; and by presenting mathematics as a bag of tricks with no internal coherence so that, instead of presenting fractions as a direct continuation of whole numbers, fractions are singled out for being "different kinds of numbers."

TSM lives on because it is being actively recycled: teachers learn TSM in K-12, go through college with their knowledge of TSM intact, and consequently have no choice but to regurgitate TSM when they

Hung-Hsi Wu is professor emeritus of mathematics at University of California, Berkeley. His email address is wu@berkeley.edu. 
teach. This is the reason why "the traditional way of teaching math simply doesn't work," provided one interprets "traditional" to mean "in the last forty years."

To give one example of how traditional teaching fails, Green relates a story in the 1980s, when the A\&W restaurant chain lost the "hamburger war" to McDonald's because the American public believed $\frac{1}{3}$ is smaller than $\frac{1}{4}$. The spectre behind this story is of course fraction phobia. But how can students not be touched by this phobia if TSM tells them, for example, to add fractions by the use of Least Common Denominator without any explanation of why this strange way of adding fractions is related to "putting things together"? When help is sought, one finds on page 96 of [NCTM1989]:

This proficiency in the addition, subtraction, and multiplication of fractions and mixed numbers should be limited to those with simple denominators that can be visualized concretely or pictorially and are apt to occur in real-world settings.... This is not to suggest, however, that valuable instruction time should be devoted to exercises like $17 / 24+5 / 18$ or $5 \frac{3}{4} \times 4 \frac{1}{4}, \ldots$.

This does nothing but add to the phobia! The pressing need is not a new way to teach the addition of fractions according to TSM, but a correct mathematical presentation of fractions that can explain the how and why of adding fractions.

We have to get rid of TSM.

NCTM and the math community should have realized all along that they share a common goal after all: to eradicate TSM. If they had, they would not have spent the last twenty-five years mainly fighting the Math Wars, and Elizabeth Green would have written a different article. But instead of eradicating TSM, NCTM unwittingly contributed to giving TSM new life, and the math community stood by-until the advent of the Common Core-to watch the deterioration of school math education.

Let us do better in the future.

\section{References}

[Green] E. GREEN, Why do Americans stink at math? www. nytimes. com/2014/07/27/magazine/why-doamericans-stink-at-math.htm7

[NCTM1989] Curriculum and Evaluation Standards for School Mathematics, National Council of Teachers of Mathematics, Reston, VA, 1989.

[Wu] H. WU, Phoenix rising: Bringing the Common core state mathematics standards to life, American Educator, fall 2011, vol. 35, no. 3, 3-13. math. berke1ey. edu/ wu/wu2011

\section{Bill Jacob}

Listening to Learners and the Role of Context Elizabeth Green describes many of the difficulties facing the Common Core State Standards in Mathematics (CCSSM). The basic problems are familiar, having appeared in earlier attempts to change K-12 mathematics. Among them are access to professional development and instructional materials addressing new expectations. Green's description of changing the script "I, We, You," emphasizing the process of answer-getting, to "You, Y'All, We," emphasizing the act of sense-making, while simplistic, does capture the gist of changing expectations of practice. However, teaching has changed little in spite of several national initiatives. So, how can collegiate mathematics educators participate? I suggest here two areas where AMS Notices readers can help bring positive change while staying clear of the politics that surrounds the CCSSM.

The change in focus from the actions of the teacher to the actions of the learner should be our first step in interactions with $\mathrm{K}-12$. Mathematicians reviewing content typically concern themselves with the ordering of topics and the accuracy of exposition. But more critical are the ideas developed by the learner when engaging in a task, be they children's "twitters" (the inchoate thoughts noted by Japanese educators) or more developed discussion. Observing and listening to students, with instructional decisions based upon these observations, are essential components of the change.

This is not easy and can turn the daily practice of a teacher who relies on a previously set script upside down. Problem solving and inquiry become the basis for instruction, not an end-of-the-line activity. Green interviewed Magdalene Lampert but did not explain how crucial her on-the-fly instructional decisions are to ensuring student progress. Doing this requires understanding the mathematics and the learner's development, and Lampert succeeded because she was immersed in both. For a number of years I have had pre- and in-service teachers read and discuss Chapter 2 of Lampert's book Teaching Problems and Problems of Teaching, and I have found that discussions of this chapter provide a solid framework for collaboration.

Second, we need to be clear about how context can ensure that learning tasks raise important mathematical ideas. The CCSSM has a modeling strand, but will it lead to important ideas or be

Bill Jacob is professor of mathematics at the University of California, Santa Barbara. His email address is jacob@math.ucsb.edu. 
relegated to a few applications? Context needs to be carefully crafted and should lead to important representations. Koeno Gravemajer said a learner should move from a "model of the context" to a "model for thinking about the underlying mathematics." For example, the context in Lampert's problem in Chapter 2 led to the development of a double number line that the students then used for proportional reasoning.

Unfortunately, the contexts students often see are those of trivialized word problems such as "How many legs are on eighty-five spiders?" Most students will appropriately see this as uninteresting. But imagine a third-grade class being asked, "How many legs are on three spiders?" Children who draw three spiders may first count the legs, but the context can elicit many strategies. Three groups of eight legs can be viewed as six groups of four when four legs are drawn on each side of a spider and viewed as a unit. A row of three spiders could be viewed as having two rows of twelve legs (top and bottom), or the legs could be counted as twelve pairs. A skilled teacher can pull from various groupings of the legs a spatial understanding of why the equivalence $8 \times 3=4 \times 6=2 \times 12=12 \times 2$ arises, beyond merely having the same value.

In a measurement context these same children might also represent subtraction as difference on a number line to make sense of the equivalence $123-88=125-90=135-100$. This is much more than a process for computation; later they will need the measurement model for subtraction in two dimensions as they unravel why $\left(y_{1}-y_{0}\right) /\left(x_{1}-x_{0}\right)$ describes slope. Learners who only understand subtraction as removal and not as difference in a measurement context will miss the meaning of $\left(y_{1}-y_{0}\right)$ and $\left(x_{1}-x_{0}\right)$ in the slope expression. As mathematicians and mathematics educators we can play an important role by helping identify contexts that lead to representations that are integral to mathematics.

Finally, we must not be divisive in our work. Green's statement that the "traditional approach does not work" demeans people who have devoted their lives to teaching, just as claims that the "rigor is lost in CCSSM" throws the solid efforts of others into a tailspin. Instead we need to participate in a process that helps teachers learn to base instructional decisions on students' mental actions and design contexts that make sense to the learner while simultaneously bringing forth important representations. If we view the CCSSM as providing an opportunity to engage all stakeholders in K-12 mathematics in a process that addresses students' mental actions with context and representation, we can move math education forward.

\section{Wayne Bishop}

\section{Why Do Americans Stink at Math?}

Ms. Green's basic premise [1] is that Japanese classrooms modified their style from the supposed "traditional" approach of rote response and memorization of meaningless algorithms to the American style of teaching mathematics following a "constructivist" approach embodied in the National Council of Teachers of Mathematics (NCTM) Standards [2] and made current by the Common Core State Standards-Mathematics [3] (albeit denied by CCSS-M supporters). Unfortunately, her article and her new book, Building a Better Teacher [4] represent a great deal of education industry misinformation that does not bode well for precollegiate mathematics education, especially for students with special math-based career aspirations but for those with less specialized needs as well.

One of her primary sources was Akihiko Takahashi, a mathematics education professor from DePaul University (originally from Japan). Another of her sources was a far better-known education professor, Magdalene Lampert. Some respected mathematicians, remembering their own precollegiate mathematics frustrations, assume that the advocated "discovery learning" is reflective of the "Moore Method" of R. L. Moore. For comparison:

In her book Teaching Problems and the Problems of Teaching [5], Lampert tells the story of how one of her fifth-grade classes learned fractions. One day, a student made a "conjecture" that reflected a common misconception among children. The fraction $\frac{5}{6}$, the student argued, goes in the same place on the number line as $\frac{5}{12}$. For the rest of the class period the student listened as a lineup of peers detailed all the reasons the two numbers couldn't possibly be equivalent, even though they had the same numerator. [1]

The article implies that this almost complete waste of zero-sum fifth-grade math time reflects the Japanese model of ordinary mathematics classrooms. By contrast, an actual Japanese classroom, as observed by Professor Takahashi:

One day, for example, the young students would derive the formula for finding the area of a rectangle; the next, they would use what they learned to do the same for parallelograms. Taught this new way, math itself seemed transformed. It was not dull misery but challenging, stimulating and even fun. [1]

Wayne Bishop is professor of mathematics at the California State University Los Angeles. His email address is wbishop@ca1state1a.edu. 
This is excellent teaching, but there is nothing new about it-in fact, "time immemorial" comes to mind. The sequence was carefully structured for students to recognize, "discover" if you wish, the formulas along with a solid understanding of why they work. Continue a little longer and students "discover" why the formula for the area of a triangle is what it is. Such classrooms were well documented in the videos associated with the 1995 Third International Math Science Study (TIMSS) that brought Singapore to the attention of the world along with its great Primary Series in elementary school mathematics. The studentoriented US classrooms spent far less time on mathematically supportable evidence than did the Japanese.

One feature on which the team members focused was deductive reasoning, a form of mathematical activity that they considered central for students' engagement in important mathematics. They defined deductive reasoning as the reasoning needed to draw logical conclusions from premises. Mathematical proofs are the most familiar form of such reasoning. As it turned out, these instances were found in 62 percent of the Japanese lessons, 21 percent of the German lessons, and 0 percent of the US lessons. [6]

NYU's Alan Siegel has provided a nice summary of these videotapes [7].

Although the growing professional education industry in Japan did make some effort to move in the Lampert (NCTM) direction in the late 1990s and early 2000s, the response from universities and students seeking admission to them was quick and self-correcting [8]:

This time protest would come from universities. And rather than educational researchers or arts instructors, it was the math and science instructors who were speaking out. [8]

Implications for Japanese classrooms can be seen in an interesting study of representative middle schools in Japan conducted by Linfield College. These classrooms were highly reminiscent of my own precollegiate experience and the way we usually conduct university-level math courses:

Students sit in rows and are expected to listen quietly. Teachers rely on direct instruction rather than investigative mathematics, but although they ask few questions, the questions they do ask are useful in guiding student understanding. [9]

Given the heavy reliance on calculators in the early grades and graphing calculators later on in American style "reform math," the following is also enlightening:
The biggest surprise was a shocking lack of technology in Japanese classrooms. "Not a single student pulled out a calculator during class," Drickey said. "But lack of reliance on technology may lead to higher scores for Japanese students," she said. "The ability to think mathematically, without the aid of an outside source, could help students process mathematical problems more accurately and efficiently." [9]

Perhaps the worst problem with Ms. Green's article was the missing "elephant in the room," a heavily used compensating factor known as juku:

Now in Japan, approximately 40 percent of elementary students and more than 70 percent of junior high students are using juku service according to an article of the Japan Times. [10]

Moreover, Mr. Watanabe, the author of the juku book [11], goes on to explain that it's much higher than 70 percent for those with university aspirations who use it as preparation for critical exams.

\section{References}

[1] www.nytimes.com/2014/07/27/magazine/why-doamericans-stink-at-math.htm 1?

[2] NCTMCurriculum and Evaluation Standards for School Mathematics, 1989, and revised as Principles and Standards for School Mathematics, 2000.

[3] Common Core State Standards-Mathematics, www. corestandards.org/Math/.

[4] ElizABeth GreEn, Building a Better Teacher, W. W. Norton, 2014.

[5] Magdalene Lampert, Teaching Problems and the Problems of Teaching, Yale University, 2001.

[6] James W. Stigler and James Hiebert, Phi Delta Kappan 79, No. 1 (September 1997), 14-21.

[7] www.cs.nyu.edu/faculty/siege1/ST11.pdf

[8] WwW.nippon.com/en/in-depth/a00601/.

[9] www.1infield.edu/linfield-news/students-andprof-examine-why-japan-outsmarts-u-s-inmath-scores/.

[10] jukuyobiko.b1ogspot.jp/2014/08/big-doubtson-ny-times-article-why-do.htm].

[11] MANABU WATANABE, JUKU: The Stealth Force of Education and the Deterioration of Schools in Japan, Achieving Coherence in Math Instruction-a response to Elizabeth Green. CreateSpace Publ., North Charleston, SC, 2013. 


\section{Roger Howe}

\section{Design Flaws of the US Education System; Subtle Virtues of CCSSM}

Elizabeth Green doubts that the Common Core Standards can succeed in improving US mathematics instruction, and the major reason she gives is right on target. In order to reap the benefits of the Common Core, what teachers do will need to change substantially. However, the US educational system is structured to discourage teacher improvement. As Green points out, to support teachers in their efforts to improve, Japan has lesson study. China has analogous structures ${ }^{1}$ and a regular system for allowing teachers to learn their craft and for the best ones to help the rest to improve. Professional development in China is largely in the hands of the teaching profession itself. Opportunities to learn from colleagues are built into the structure of a teacher's day. Standout education systems such as Singapore's and Finland's have also adopted similar structures. By contrast, instruction, in the sense of standing in front of a class of students, is the all-absorbing activity of US teachers. Efforts to improve one's own knowledge or craft are left to individual initiative and spare time. It should not be surprising to any intelligent policymaker that they are less than we need.

Judging teachers by the results of standardized tests will not improve things. The key problem with the US educational system is summarized in the relative unattractiveness of the job. We don't have the teaching corps we want because the rewards are not commensurate with the challenge. To become a teacher here is not hard: standards for certification are low. But to stay in teaching is hard. The starting and continuing salary are relatively low. The market discourages people from teaching. This is reflected in the relative college GPA of teacher candidates. The job is tough. This is reflected in the high attrition rates during the first years of teaching. The modal number of years in the job is one. Using standardized tests to judge teachers will make the job even less attractive. This is not what the system needs. In fact, the premise of NCLB, that standardized testing can improve results, is false according to most current evidence. It is a major mistake of the Obama administration to double down on the testing and use tests to judge teachers also.

Despite the well-founded reasons for pessimism, we should not lose sight of the positive aspects of

Roger Howe is professor of mathematics at Yale University. His email address is howe@math.yale.edu.

${ }^{1}$ Teacher Development Continuum in the United States and China (Summary of a Workshop), National Academies Press, 2010. the CCSSM, which may promote improvement in the longer term. The CCSSM by and large are an improvement over almost all the standards they replace, and they make especially significant steps to reduce the chaos in our mathematics curriculum. Overall, they are indeed "fewer, deeper, higher."

However, categories like "rigor" and "focus" largely miss some notable virtues of the CCSSM: they are technically better on several key topics than any of their predecessors. For example, place value is the fundamental idea we use to represent large numbers and to compute and estimate. It has been an area of glaring weakness in the US curriculum for decades, perhaps always. The CCSSM introduce notable improvements, including advocating "addition and subtraction within 20" as the approach of choice for starting to learn about multidigit computation and emphasizing place value issues at several later points. This superior approach to the beginnings of place value has been implemented in several high-performing countries but was largely missing in the US, even after the reforms of the 1990s.

Another promising feature of CCSSM is its approach to fractions through unit fractions. This approach puts a much greater emphasis on units and the relations between them and stands a much better chance of promoting thinking of numbers in terms of how they are actually used: to express quantity relationships rather than simply being counts. In some seminars with teachers, I have found that they readily, even enthusiastically, adopt these new approaches and see them as improvements. If states will step up to their responsibilities and create adequate professional development opportunities for teachers, the country can benefit from these improved approaches to key topics which have been incorporated in the CCSSM.

\section{Guershon Harel}

\section{On the Complexity of Mathematics Teaching: A Reaction to Green's Article}

Given the publicity that Green's article has generated, it is important to address certain statements in the article that seem unremarkable or selfevident but, in fact, cognitively and pedagogically are complex. Due to space limitation, I chose to focus on a few such statements.

A highlight of the Japanese classroom described by Green is that "instead of having students memorize and then practice endless lists of equations ...[teachers are taught] to encourage passionate

Guershon Harel is professor of mathematics at the University of California, San Diego. His email address is hare1@math . ucsd. edu. 
discussions among children so that they would come to uncover math's procedures, properties and proofs for themselves." Educators largely agree that mere memorization is harmful, but this statement gives the impression that "endless lists of equations" is equally bad. Not so. The practice, with understanding, of large numbers of equations of different kinds and structures is essential for students to develop a critical way of thinking: that by which one recognizes that algebraic expressions are manipulated not haphazardly but with the purpose of arriving at a desired form and maintaining certain properties of the expression invariant. This pedagogical approach falls under a more general learning principle called the repeated reasoning principle. It states that, students must practice reasoning in order to internalize, organize, and retain concepts and ideas. It is repeated reasoning, not mere drill and practice of routine problems, that enables students to be able to apply knowledge autonomously and spontaneously.

Green discusses this "new" Japanese teaching as a prelude to her claim that "...today's Common Core math [stems] from the idea that the traditional way of teaching math simply does not work." It is important to recognize that the Common Core is not about how to teach mathematics; rather, it is about the mathematics that should be taught. It is, however, true that the mathematics depicted in the Common Core demands particular ways of teaching. I explain.

In my view, the single most important new element in the Common Core relative to previous reforms is the explicit incorporation of mathematical practices or ways of thinking. In essence, we have here recognition that mathematics is not just subject matter-a collection of definitions, theorems, proofs, problems and their solutions, algorithms, etc.-but also includes ways of thinking. This recognition implies that instructional objectives should be formulated in terms of both subject matter and ways of thinking, not only in terms of the former, as is typically the case in traditional mathematics curricula. Following up on my earlier point on practice of equations, the method of completing the square, for example, would be taught not just as a method for solving quadratic equations but also as an opportunity to advance students toward acquiring the habit of mind of manipulating symbols with purpose in mind. Assuming the students have already learned how to solve equations of the form $(x+T)^{2}=L$, the teacher's action would be geared toward helping them manipulate the quadratic equation $a x^{2}+b x+c=0$ with the goal of transforming it into the known equation form while maintaining the solution set unchanged, thereby advancing students' attention to structure. The gain in this approach is twofold: deeper understanding of concepts (e.g., the concept of equation) and ways of thinking (e.g., attention to structure).

Unfortunately, teachers are not ready for this view of mathematics and mathematics teaching. Nor are our teachers equipped with the pedagogical content knowledge to help students uncover mathematical ideas. Indeed, the main concern of current mathematics curricula is covering rather than uncovering mathematical content. The term "uncover" is problematic, and some of the statements in Green's article raise the need to clarify it. For example, Green's statement that “... [students] would come to uncover math's procedures, properties and proofs for themselves" may reflect a simplistic and practically unrealistic position: that students should not be told directly a mathematical idea but let them develop it on their own. The practical and pedagogically effective question to ask is not "To tell or not to tell?" but "When to tell and when not to tell?" An important guide for this question is the learning principle of intellectual need, called the necessity principle. It states that for students to learn what we intend to teach them, they must have a need for it, where "need" refers to intellectual need, not social or economic need. This principle implies that new concepts and skills should emerge from problems understood and appreciated as such by the students, and these problems should demonstrate to the student the intellectual benefit of the concept (not necessarily its application in the "real world") at the time of its introduction. Once students are judged by their teacher to have developed an intellectual need for a concept, they are in a proper cognitive state to be presented with that concept. It is neither necessary nor practical that they uncover the concept on their own.

In sum, attention to the complexities of mathematics teaching rather than just broad educational issues such as those discussed in Green's paper is essential to the success of the Common Core reform. Judging by the current mathematics textbooks, including those claiming to be Common Core-based, current teachers' knowledge, and the quality of our teacher preparation and professional development programs, it is evident to me that monumental work is still ahead of us to ensure the success of this reform. 